\title{
A domain specific software model for interior architectural education and practice
}

\author{
Burcu Șenyapılı* , Burcu Gökçen Bozdağ \\ Bilkent University, Faculty of Art, Design and Architecture, Department of Interior Architecture and Environmental Design, 06800 Bilkent, Ankara, Turkey
}

\section{A R T I C L E I N F O}

\section{Article history:}

Accepted 11 May 2011

Available online 31 May 2011

\section{Keywords:}

Computer aided architectural design

Domain specific software

General-purpose software

Interior architecture

Software features

\begin{abstract}
A B S T R A C T
Interior architectural education and practice employ various general-purpose software packages. This study problematizes that as none of these packages is developed specifically for interior architectural design process and purposes, both interior architecture education and market seek ways to fulfill their specific needs. It is argued that currently interior architecture does not fully benefit from digital opportunities. A specific software package for interior architecture will enable the discipline to put forth its assets and manifest its existence. Consequently, this study proposes a domain specific model for interior architectural software.

Initially, general-purpose and domain specific computer aided architectural design (CAAD) software used in interior architecture are determined. Then, selected software packages are analyzed according to Szalapaj's [1] set of features: 'drawing', 'transformation', 'view', 'rendering' and 'other'. Based on these analyses, domain specific requirements for interior architecture are obtained. Consequently, questionnaires and interviews are performed with interior architectural students and professionals in order to determine the user needs. Finally, based on the findings, a software model for interior architecture is proposed.
\end{abstract}

(c) 2011 Elsevier B.V. All rights reserved.

\section{Introduction}

Computer aided architectural design (CAAD) software packages are mostly developed for general-purpose use and then they are customized to serve for specific needs [2,3]. Most software packages used in interior architecture are such general-purpose software, which are originally developed for architecture. Often, customization of these packages to meet fundamental requirements of interior architectural design process is left to the user. Most of the interior architectural companies utilize bespoke or general CAAD software by integrating plug-ins [4]. Similar to many other professions, today interior architectural companies are becoming more dependent upon digital technologies and software packages for their daily operations [5], thus the number of individual software packages used in interior architectural practice increases. However, a domain specific interior architectural software package, which is widely accepted and used, is not existent.

Interior architecture is a distinct design field which specializes in interior space's detailed design requirements related to color, texture, lighting, heating, acoustics, furniture and all details of human use [6,7] and actually, it owes its independent existence as a field to these details. These details put forth a special characteristic for interior architecture and express its "otherness" [8]. However, interior architecture still struggles to manifest its existence; deprived of connotations of decoration and sublimed from the subduing effects of

\footnotetext{
* Corresponding author. Tel.: + 90312290 1737; fax: + 903124416291.

E-mail addresses: burcu@bilkent.edu.tr (B. Şenyapılı), burcugok@bilkent.edu.tr (B.G. Bozdağ).
}

architecture. Often, interior architecture is merely taken as decorating the space that could even be done by those who are interested and tasty, with no formal education, and/or it is overlooked as already being taken care of within the architectural agenda.

This dilemma has already obstructed interior architecture from benefiting from the medium of computer fully. Currently, the available software for interior architecture reflects the quandary about interior architecture. On one hand, there are how-to-do-ityourself packages that reduce the process to selecting from a bundle; totally reducing the process of design to a series of selections. On the other, there are general-purpose packages that encompass architectural shell making, comprising all the details of the shell and its making. Using the latter packages is like taking a plane to go to the grocery store, in other words, it is employing an over-equipped a tool for an otherwise too random a function for interior architecture.

In fact, given the right tools, the digital opportunities could enable interior architecture to assert itself by putting forth its differences and potentials in terms of creating and assessing spaces with color, light, materials and sounds, which could eventually alter the way how the profession is perceived. Interior architecture is concerned with the changing effects of light on different colors and materials, the manipulation of sound within a space and the quality of the interior space in terms of issues pertaining to sustainability, like heat distribution in a space or ventilation. These issues can be displayed through digital opportunities better than in any other medium, largely because real-time animations are possible.

Surprisingly, with the advancements of the technology interior architecture looses the grip of its design field, instead of having the upper hand. Not only contractors are producing optimized interiors 
Methodology

\section{Comparative Software Analysis \\ - General-purposed Software Analysis \\ - Domain Specific Software Analysis \\ - General-purpose versus Domain Specific Software}

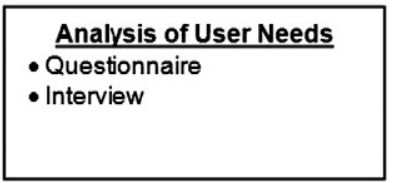

Fig. 1. Analyses of the study.

based on cliché visions, which are nonetheless professional looking thanks to the computer aid; even clients are becoming capable of creating their own images of the interiors through the do-it-yourself packages [9].

It has been long since academia realized that adding CAAD courses to their curricula would improve students' marketability $[10,11]$. In interior architectural education, general-purpose CAAD software packages are taught $[12,13]$. There are efforts to develop software packages to serve for particular areas of interior architecture and integrate them to the curriculum, yet these remain separate and experiential [14-18]. Interior architecture students who learn using general-purpose software during their education, often have difficulties when they start working in interior architectural companies, as they need to get accustomed to the bespoke software package the company uses. One of the reasons for this difficult adaptation process is the different approaches to design between general-purpose software and bespoke ones.

The assets of interior architecture (like color, light, texture, materials, acoustics) are usually overlooked in the overpopulated services provided by the general-purpose software, and/or experiencing them requires the prerequisite of a shell to be developed first, whereas they take the central stage in the bespoke packages. Teaching all the bespoke packages would be impossible and pointless. However, integrating the issues that are standing up in the bespoke ones into a domain specific package could speed up the profession both in revealing itself in full force, and getting rid of unnecessary bulks of the packages.

Within this framework, it is worth investigating how a domain specific CAAD software would be built for interior architectural requirements and what would be the specific issues to be taken into consideration while establishing domain specific software for interior architecture?

\section{Methodology}

In order to answer the above question, this study analyzes three components:

1. Features of the commonly used CAAD software in interior architecture

2. Domain requirements of interior architecture

3. User (student and professional) needs.

These analyses are made with the assumptions that:

1. General-purpose CAAD software packages are not sufficient in meeting the needs of interior architectural design.

2. In order to meet their specific needs, interior architectural students utilize general-purpose or architectural domain specific CAAD software during their design process, whereas interior architectural professionals use customized software (Customized software may be developed specifically for a firm or they may be developed by adding plug-ins to general-purpose software).

3. Interior architectural design students and professionals need domain specific CAAD software that serves for detailed interior architectural requirements (color, lighting, material, furniture, etc.).
Within this framework initially, commonly used CAAD software packages in interior architecture are analyzed in order to understand whether they suffice the requirements of interior architecture fully or not.

The comparative analyses of software packages are followed by questionnaires with students and in-depth interviews with professionals (Fig. 1). These analyses helped to determine the required features of interior architectural software.

Based on these analyses, a domain specific software model for interior architectural design process and purposes is proposed. This model brings together two sets of feature lists - the one gathered from comparative analyses of general-purpose and domain specific software, and the list of user needs. This model can be used as a reference for establishing domain specific CAAD software for interior architects.

\subsection{Comparative Analysis of Software Packages}

The analyzed software packages in this study are classified as 'general-purpose' and 'domain specific'. General-purpose software packages are developed to serve for a wide range of tasks or requirements. Domain specific software packages are developed to address a specific set of tasks or requirements. General-purpose software may be customized to obtain domain specific software, which shall meet specific needs in the market.

General-purpose software packages, analyzed in this study, are AutoCAD, ${ }^{1}$ 3D Studio MAX ${ }^{2}$ and ArchiCAD ${ }^{3}$ and domain specific ones are Giotto, ${ }^{4}$ Arcon ${ }^{5}$ and WebDekor. ${ }^{6}$ The general-purpose software are chosen due to their wide spread use and long existence in the market, as well as their varied utilization in 2D drawing, 3D modeling and building information modeling (BIM) $[4,19]$. The domain specific packages are chosen so that they address particular areas of interior architectural design like kitchen, bathroom and ceramic design respectively.

Based on the categorization made by Szalapaj [1], general-purpose and domain specific CAAD software packages are compared to each other regarding their features related to;

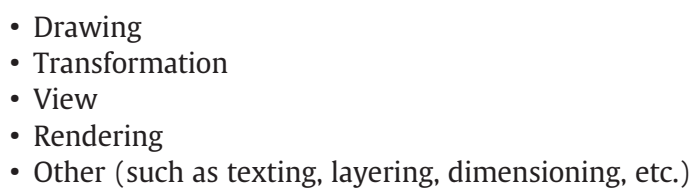

\subsection{Analysis of user preferences}

User preferences are obtained through questionnaires with students and interviews with professionals.

\footnotetext{
1 AutoCAD is a registered trademark of AutoDesk

2 3D Studio MAX is a registered trademark of AutoDesk.

${ }^{3}$ ArchiCAD is a registered trademark of Graphisoft.

${ }^{4}$ Giotto is a registered trademark of Computer Office.

5 Arcon is a registered trademark of Eleco.

${ }^{6}$ WebDekor is a registered trademark of Virtual Décor.
} 

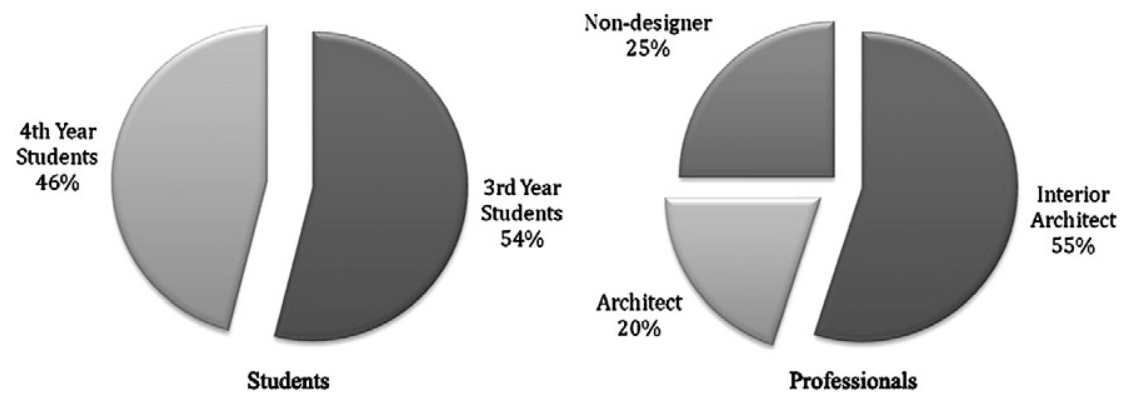

Fig. 2. Distributions of participants.

Students, who participated in the study, are junior and senior students in an interior architecture curriculum. 3rd and 4th year design students are preferred because they have completed the basic CAAD courses in the curriculum. The total number of students is 112; 60 junior and 52 senior (Fig. 2). Nineteen percent of the students are male and $81 \%$ of them are female.

20 professionals participated in the study. These professionals are randomly selected from different companies, which are specialized in different areas of interior architectural design and decoration, such as kitchen, bathroom and bedroom. 16 of interviewees are experienced specifically in kitchen, bathroom and bedroom design, and 4 of them are experienced in interior architectural design in general. Among the 20 interviewees, 11 of them are interior architects, 5 of them are architects and 4 of them are non-designers (i.e. originally from other professions) whilst 60 percent of the interviewees are female and the rest 40 percent are male (Fig. 2).

\section{Findings}

The findings are grouped as:

1. Findings related to the comparative analysis of software packages

2. Findings related to the user preferences.

The first group of findings gives the results of an objective comparison of features of specified domain specific and generalpurpose software packages. The comparisons form a matrix of features of the software packages.

Second group of findings tends to be more subjective depending on the user's perspective. The result of questionnaires and interviews helps to identify software packages that are commonly preferred by professionals and students. Also, user needs in terms of software features and quality attributes are presented in the findings.

\subsection{Findings of comparative analysis of software packages}

The main purpose of the comparative software feature evaluations is to determine the gaps and overlaps between general-purpose and domain specific software in order to obtain the set of interior architectural domain requirements.

Table 1 demonstrates the comparison of the general-purpose and domain specific software features.

The findings reveal the following:

1. Comparisons in 'drawing' features show that although generalpurpose software are ideal for drawing fundamental objects, they are insufficient in drawing interior architectural ones. For instance, ArchiCAD, which is an architectural software package, is not very flexible of drawing interior architectural objects and symbols. On the other hand, domain specific software packages allow drawing interior architectural objects easily. However, they serve for a limited area of use often confined to a specific interior space. For instance, Giotto is a flexible package for drawing kitchen objects and symbols, whereas Arcon aids in drawing bathroom objects and symbols. Overall no software package meets all of the items specified in 'drawing' features.

2. In 'transformation' features, 3D Studio Max meets all the requirements, being the most inclusive software package in $3 \mathrm{D}$ modeling field.

3. In 'view' features, all of the software packages analyzed embrace most of the features listed.

4. In 'rendering' features, 3D Studio Max meets all of the given requirements. Although domain specific software packages offer 'global rendering' methods, these methods are not as effective as the general-purpose software packages, in providing photorealistic images.

5. Although all software packages meet the requirements in the 'other' features list, 'cost estimation' feature differentiates domain specific packages from general-purpose software packages.

Overall evaluations of features revealed that Arcon is the most effective package among all other software packages examined. One of reasons behind Arcon's success may be its being transformed from a general-purpose software package by a plug-in, thus comprising many of the features.

Table 2 represents an overview of the comparison of features in general-purpose and domain specific software packages.

\subsection{Findings of user preferences}

User preferences are analyzed under two categories. First, students' and professionals' preferences in choosing software packages for design process are examined. For deeper analysis, the design process is divided into three phases: as conceptual, development and presentation. Software preferences for each phase are examined.

Secondly, user needs are investigated through questionnaires and interviews. Results are classified as software features and quality attributes.

\subsubsection{Commonly used software packages}

According to the analyses, $75 \%$ of the students and $100 \%$ of the professionals, who participated in the study, utilize software aid in their design process. The participating students have been using computers for an average of 1.7 years and professionals for 6.75 years.

AutoCAD, which is a general-purpose 2D drawing and 3D modeling software, is found out to be the most commonly used software package in interior architectural education and practice. AutoCAD is followed by Arcon, 3D Studio Max, Photoshop, ${ }^{7}$ SketchUp ${ }^{8}$ and ArchiCAD (Fig. 3). The software packages that are not as much utilized as the above are grouped as 'other': These packages are

\footnotetext{
${ }^{7}$ Photoshop is a registered trademark of Adobe Systems Inc.

${ }^{8}$ SketchUp is a registered trademark of Google.
} 
Table 1

Comparison of General-purpose and Domain Specific CAAD Software.

\begin{tabular}{|c|c|c|c|c|c|c|c|c|c|}
\hline & & & & AutoCAD & 3Ds MAX & ArchiCAD & Giotto & Arcon & WebDekor \\
\hline \multirow[t]{22}{*}{ DRAWING } & \multirow[t]{11}{*}{ 2D Objects 2D Symbols } & \multicolumn{2}{|l|}{ Line Types } & * & $*$ & $*$ & $*$ & $*$ & * \\
\hline & & \multicolumn{2}{|l|}{ Shapes } & * & $*$ & $*$ & $*$ & $*$ & \\
\hline & & \multicolumn{2}{|l|}{ Grids } & $*$ & $*$ & $*$ & & $*$ & \\
\hline & & \multicolumn{2}{|l|}{ Dimension } & * & & $*$ & $*$ & $*$ & \\
\hline & & \multicolumn{2}{|l|}{ Architectural } & * & & $*$ & $*$ & $*$ & \\
\hline & & \multicolumn{2}{|l|}{ Engineering } & * & & $*$ & * & & \\
\hline & & Landscape & & $*$ & & $*$ & $*$ & $*$ & \\
\hline & & Interior & Kitchen & & & & $*$ & & * \\
\hline & & & Bathroom & & & & & $*$ & * \\
\hline & & & Furniture & & & & $*$ & $*$ & * \\
\hline & & & Accessories & & & & $*$ & $*$ & * \\
\hline & 3D Objects & Planes & & $*$ & * & $*$ & $*$ & $*$ & * \\
\hline & & Volumes & & $*$ & * & $*$ & $*$ & $*$ & $*$ \\
\hline & & Quadric Surfaces & & & $*$ & & & & \\
\hline & & High-Order Surfaces & & & $*$ & & & & \\
\hline & 3D Elements & Architectural & & & & $*$ & $*$ & * & * \\
\hline & & Engineering & & & & & $*$ & & \\
\hline & & Landscape & & & & $*$ & $*$ & $*$ & \\
\hline & & Interior & Kitchen & & & & $*$ & & $*$ \\
\hline & & & Bathroom & & & & & $*$ & \\
\hline & & & Furniture & & & & $*$ & $*$ & * \\
\hline & & & Accessories & & & & $*$ & $*$ & $*$ \\
\hline TRANSFORMATIONS & Geometric Transformations & Copy & & & $*$ & $*$ & $*$ & $*$ & * \\
\hline & & Mirror & & $*$ & $*$ & $*$ & $*$ & $*$ & * \\
\hline & & Array & & * & $*$ & $*$ & $*$ & $*$ & * \\
\hline & & Offset & & * & * & * & * & * & * \\
\hline & & Erase & & * & $*$ & $*$ & $*$ & $*$ & $*$ \\
\hline & & Move & & $*$ & $*$ & $*$ & $*$ & $*$ & * \\
\hline & & Scale & & * & $*$ & $*$ & $*$ & $*$ & $*$ \\
\hline & & Rotate & & * & $*$ & $*$ & $*$ & $*$ & $*$ \\
\hline & & Stretch & & $*$ & * & $*$ & & $*$ & $*$ \\
\hline & & Extend & & * & $*$ & $*$ & & $*$ & \\
\hline & & Trim & & * & * & $*$ & $*$ & $*$ & \\
\hline & & 3D Mirror & & $*$ & * & $*$ & & & \\
\hline & & 3D Array & & $*$ & $*$ & $*$ & $*$ & $*$ & $*$ \\
\hline & & 3D Move & & $*$ & $*$ & $*$ & $*$ & $*$ & $*$ \\
\hline & & 3D Rotate & & $*$ & $*$ & $*$ & $*$ & $*$ & $*$ \\
\hline & Geometric Deformations & Bend & & & $*$ & & & & \\
\hline & & Taper & & & $*$ & & & & \\
\hline & & Twist & & & * & & & & \\
\hline & Topological T. & Extrude & & $*$ & * & $*$ & $*$ & $*$ & * \\
\hline & & Sweep & & & * & & & & \\
\hline & & Loft & & & $*$ & & & & \\
\hline & & Wave & & & * & & & & \\
\hline & & Noise & & & $*$ & & & & \\
\hline & Boolean Operations & Union & & $*$ & $*$ & $*$ & & $*$ & \\
\hline & & Subtract & & * & $*$ & $*$ & & $*$ & \\
\hline & & Intersect & & $*$ & $*$ & $*$ & & $*$ & \\
\hline VIEW & 2D View & Zoom & & * & $*$ & $*$ & * & $*$ & $*$ \\
\hline & & Pan & & * & $*$ & $*$ & $*$ & & $*$ \\
\hline & & 2D Wireframe & & $*$ & $*$ & $*$ & $*$ & $*$ & $*$ \\
\hline & & 2D Hidden & & $*$ & & & & & \\
\hline & & View ports & & $*$ & $*$ & $*$ & $*$ & $*$ & \\
\hline & & 2D Section View & & & & $*$ & $*$ & $*$ & \\
\hline & 3D View & 3D Wireframe & & * & $*$ & $*$ & & $*$ & \\
\hline & & 3D Hidden & & $*$ & $*$ & $*$ & $*$ & $*$ & $*$ \\
\hline & & 3D Shaded & & $*$ & $*$ & * & $*$ & $*$ & $*$ \\
\hline & & Perspective & & * & $*$ & $*$ & $*$ & $*$ & $*$ \\
\hline & & Axonometric & & $*$ & $*$ & $*$ & & & \\
\hline & & 3D Section View & & & & $*$ & $*$ & $*$ & \\
\hline & & 3D Orbit & & * & $*$ & $*$ & $*$ & $*$ & $*$ \\
\hline & & Camera & & $*$ & $*$ & $*$ & $*$ & $*$ & * \\
\hline & & Animation & & & $*$ & & & $*$ & \\
\hline RENDERING & Material Library & Texture Library & & * & * & $*$ & $*$ & * & $*$ \\
\hline & & Color Library & & $*$ & $*$ & $*$ & $*$ & $*$ & $*$ \\
\hline & Material Operations & Material Creation & & $*$ & $*$ & $*$ & & $*$ & \\
\hline & & Material Editing & & $*$ & $*$ & $*$ & & $*$ & \\
\hline & & Material Import & & $*$ & $*$ & * & & $*$ & \\
\hline & & Mapping Direction & & $*$ & $*$ & $*$ & $*$ & $*$ & $*$ \\
\hline & & Mapping Frequency & & & $*$ & & $*$ & $*$ & $*$ \\
\hline & & Texture Mapping & & & $*$ & & $*$ & $*$ & $*$ \\
\hline
\end{tabular}


Table 1 (continued)

\begin{tabular}{|c|c|c|c|c|c|c|c|c|}
\hline & & & AutoCAD & 3Ds MAX & ArchiCAD & Giotto & Arcon & WebDekor \\
\hline & Lighting Elements & Spotlight & & $*$ & * & & & \\
\hline & & Direct Light & & * & & & & \\
\hline & & Sunlight & $*$ & $*$ & $*$ & $*$ & $*$ & \\
\hline & & Omni & & $*$ & & $*$ & & $*$ \\
\hline & Light Editing Operations & Radiosity & $*$ & $*$ & & $*$ & & \\
\hline & & Intensity & & $*$ & & * & $*$ & \\
\hline & & Brightness & & * & $*$ & $*$ & * & $*$ \\
\hline & & Shading & $*$ & $*$ & $*$ & $*$ & $*$ & $*$ \\
\hline & & Reflection & $*$ & * & * & $*$ & $*$ & \\
\hline & & Refraction & & $*$ & & $*$ & & \\
\hline & Rendering Method & Local Rendering & * & $*$ & $*$ & $*$ & $*$ & $*$ \\
\hline & & Global Rendering & $*$ & $*$ & $*$ & * & * & $*$ \\
\hline \multirow[t]{8}{*}{ OTHER } & Grouping & & $*$ & $*$ & $*$ & & $*$ & \\
\hline & Typing & & & & $*$ & * & * & $*$ \\
\hline & Layering & & $*$ & & $*$ & $*$ & $*$ & \\
\hline & Texting & & $*$ & $*$ & $*$ & $*$ & $*$ & $*$ \\
\hline & Hatching & & $*$ & & $*$ & $*$ & * & \\
\hline & Dimensioning & & $*$ & & $*$ & * & * & \\
\hline & Calculation (area etc.) & & $*$ & & * & $*$ & $*$ & $*$ \\
\hline & Cost Estimation & & & & & & & \\
\hline
\end{tabular}

namely Rhinoceros, ${ }^{9}$ Outline 3D, ${ }^{10}$ Paint, ${ }^{11}$ 3D Home Architect, ${ }^{12}$ Illustrator, ${ }^{13}$ Paint Shop Pro, ${ }^{14}$ Allplan, ${ }^{15}$ Corel Draw, ${ }^{16}$ Carrara, ${ }^{17}$ Kareo, ${ }^{18}$ Maya, ${ }^{19}$ Microsoft Frontpage, ${ }^{20} 20 * 20,{ }^{21}$ IntelliCAD, ${ }^{22}$ Infowood, ${ }^{23}$ TepeCAD, ${ }^{24}$ PenCAD ${ }^{25}$ and Microstation v8. ${ }^{26}$

A typical architectural design process involves several activities that occur in a logical sequence. Although these activities may vary and overlap according to different projects and architects, there are a lot of researches going on to identify the phases of design process [20,21]. Kim [22] defined the architectural design process as 'conceptual design and programming', 'schematic design', 'design development', 'constructing documentation' and 'construction supervision'. In this study, the design process is divided into three main phases; conceptual design, project development and presentation phase, for further investigation on the software preferences.

3.2.1.1. Conceptual design phase. Fig. 4 shows the percentage distributions of the software utilized in conceptual design phase. $37 \%$ of students utilize Photoshop (37\%), which verifies the importance of 2D design and rendering in conceptual design phase. $25 \%$ of the students prefer AutoCAD in this phase. In professional practice, $34 \%$ of the professionals prefer to use AutoCAD.

3.2.1.2. Project development phase. Fig. 5 shows that AutoCAD is the most popular software in this phase with $72 \%$ of students' and $42 \%$ of professionals' preferences.

\footnotetext{
${ }^{9}$ Rhinoceros is a registered trademark of Robert McNeel and Ass.

10 Outline 3D is a registered trademark of Parallel Graphics.

11 Paint is a registered trademark of Microsoft Corporation.

12 3D Home Architect is a registered trademark of Broderbund.

13 Illustrator is a registered trademark of Adobe Systems Inc

14 Paint Shop Pro is a registered trademark of Corel Corporation.

15 Allplan is a registered trademark of Nemetschek Systems.

16 Corel Draw is a registered trademark of Corel Corporation.

17 Carrara is a registered trademark of DAZ 3D.

18 Kareo is a registered trademark of White CAD.

19 Maya is a registered trademark of AutoDesk Inc.

20 Microsoft Frontpage is a registered trademark of Microsoft Corporation.

$2120-20$ is a registered trademark of 20-20 Technologies.

22 IntelliCAD is a registered trademark of IntelliCAD.

23 Infowood is a registered trademark of Design Effective.

24 TepeCAD is a registered trademark of Tepe group Ltd.

25 PenCAD is a registered trademark of ABT Yazılım.

${ }^{26}$ Microstation is a registered trademark of Bentley.
}

3.2.1.3. Presentation phase. In this phase, since the 2D and 3D drawings and representations are crucial, software packages possessing extensive 2D and 3D drawing features gain importance. AutoCAD is again the most commonly utilized software in education with $41 \%$ of student and with $21 \%$ of professionals' ratings (Fig. 6).

\subsubsection{User needs}

Having determined the utilized software, the next step is to determine whether users find these software packages sufficient, and whether there is need and tendency to use domain specific software package.

Initially, students and professionals are asked whether they find existing general-purpose CAAD software sufficient or not (Fig. 7).

Another question investigated the need for domain specific CAD software package in interior architecture. Most of the students and professionals agreed that there is need for domain specific software packages in interior architecture (Fig. 8) and most of them have a tendency to use that software packages (Fig. 9).

In an interior architectural domain specific software package, 'photo-realistic rendering' feature turns out to be one of the most important criterion that professionals seek (Fig. 10).

During the questionnaire and interviews, user needs are gathered through multiple choice and open-ended questions. In the multiple choice questions the given criteria, among which the users selected, are;

- photo-realistic image rendering

- Easy transition from 2D into 3D

- Easy transformation of 3D objects

- A shorter processing time

- Ease of learning

- A rich furniture library

- Objects texturing features

- Flexibility in creating new objects

- An user-friendly graphical user interface (GUI)

Overall results indicate that 'photo-realistic image rendering' is the most important criterion selected both by professionals and students (Fig. 11).

\subsubsection{Software Features and Software Quality Attributes}

Open-ended questions urged the users to specify their needs from an interior architectural software package. These needs are classified into two groups; software features and software quality attributes. 
Table 2

Comparison of features in general-purpose and domain specific software.

\begin{tabular}{|c|c|c|}
\hline Software Features & General-purpose Software & Domain Specific Software \\
\hline \multirow[t]{5}{*}{ DRAWING } & Quadric Surfaces & None \\
\hline & High-order Surfaces & None \\
\hline & None & 2D and 3D Interior \\
\hline & & Architectural Symbols \\
\hline & None & 3D Engineering Symbols \\
\hline \multirow[t]{2}{*}{ TRANSFORMATION } & $\begin{array}{l}\text { Geometric Transformations } \\
\text { as 3D Mirror, Bend, Taper, } \\
\text { Twist }\end{array}$ & None \\
\hline & $\begin{array}{l}\text { Topological Transformations } \\
\text { as Sweep, Loft, Wave, Noise }\end{array}$ & None \\
\hline \multirow[t]{2}{*}{ VIEW } & 2D View as 2D Hidden & None \\
\hline & 3D View as Axonometric View & None \\
\hline \multirow[t]{2}{*}{ RENDERING } & None & Light Editing as Resolution \\
\hline & $\begin{array}{l}\text { Lighting Elements as Spotlight } \\
\text { and Direct Light }\end{array}$ & None \\
\hline OTHER FEATURES & None & Cost Estimation \\
\hline
\end{tabular}

Software features affect how the software system functions and they are grouped as 'drawing', 'transformation', 'view', 'rendering' and 'other' features.

Software quality attributes affect the quality of software and involve 'ease of use', 'reliability', 'efficiency', 'flexibility' and 'other' attributes.

Table 3 embodies the analysis of software features. Professionals' needs in terms of 'drawing' features are more limited compared to the students'. Students required specific and extensive 'architectural and landscape libraries', whereas the professionals did not. The requirements of students and professionals are similar in terms of 'transformation', 'view' and 'rendering' issues. Students wish to have all of the features meeting interior architectural domain requirements, but they also want a domain specific software to resemble the general-purpose software packages they use, like AutoCAD and 3D Studio Max.

Table 4 displays user needs in terms of software quality attributes. The quality attributes unveil the hidden factors behind software features that a software package must have. The users wish to have an easier to use, more reliable, more efficient and a more flexible software package for the design process. Providing 'interoperability' and 'collaboration' during the design process, 'resemblance to the hand-drawing' and 'being an attractive software package' are also factors affecting software quality.

Percentage distribution of preferences in terms of software features and quality attributes represents that 'ease of use' is the most important feature among students and professionals (Fig. 12).

\section{Discussion}

A recent study revealed that students are willing to use computers for designing and presenting their works [23]. In line with that study, the findings of this study broadens the perspective of the use of computers and puts forth the preferred software for specific design work, and reveals the features expected from a domain specific package.

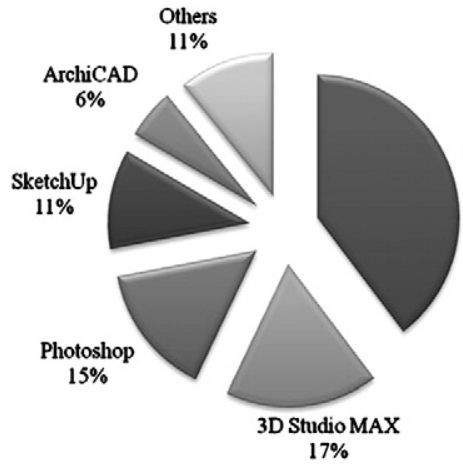

Students

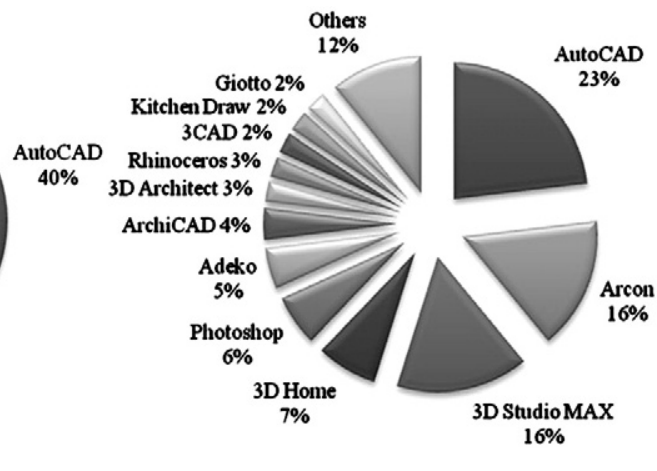

Professionals

Fig. 3. Percentage distributions of software packages.
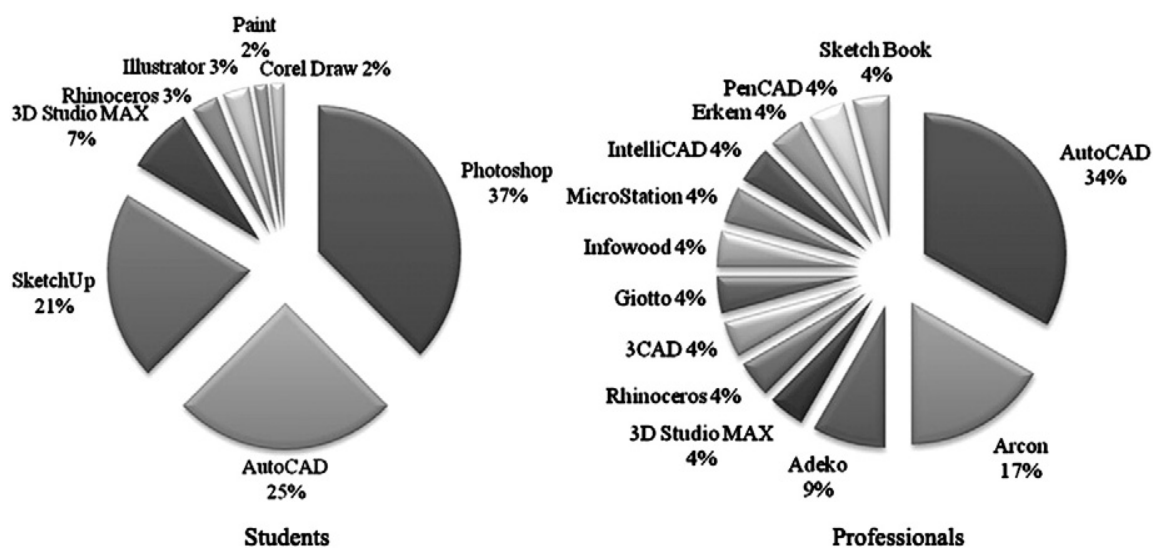

Fig. 4. Percentage distributions of the use of software packages in conceptual design phase. 


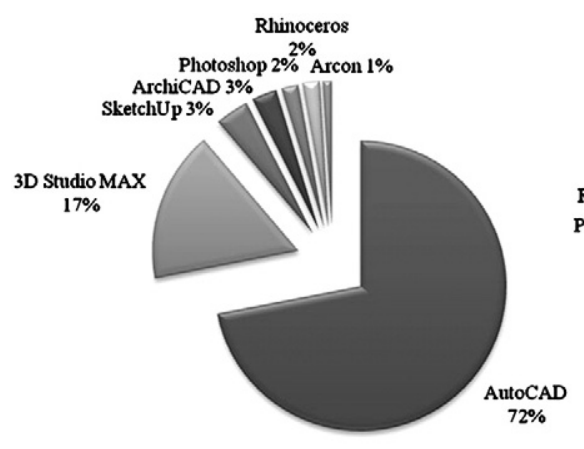

Students

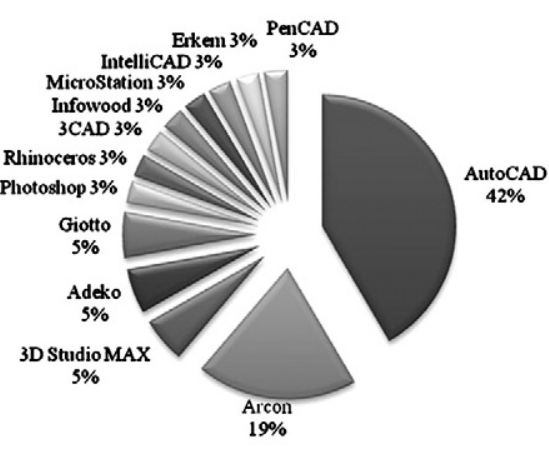

Professionals

Fig. 5. Percentage distributions of the use software packages in project development phase.
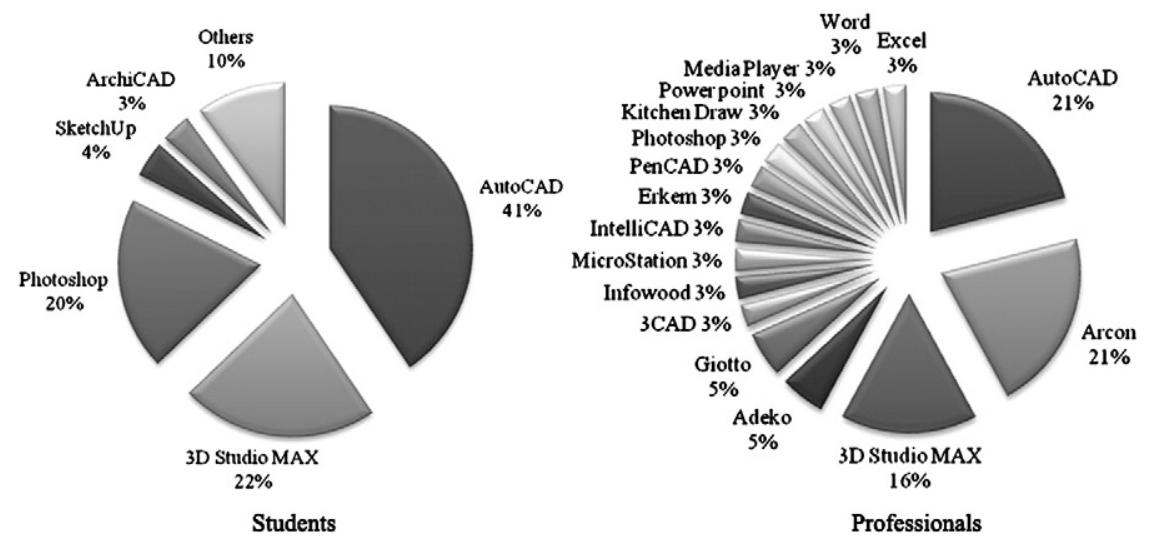

Fig. 6. Percentage distribution of the use of software packages in presentation phase.

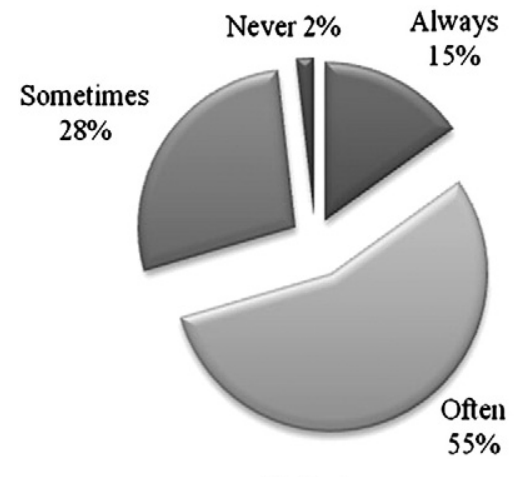

Students

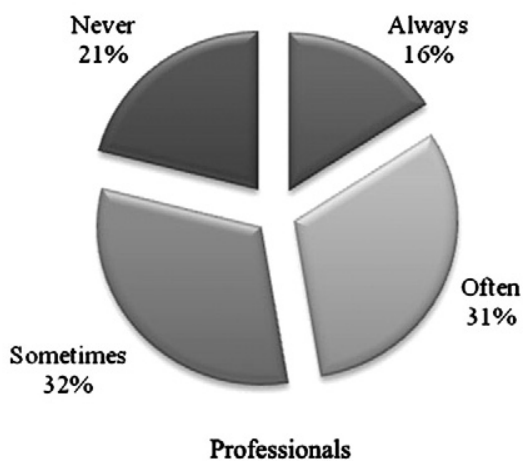

Professionals

Fig. 7. Percentage distribution of satisfaction with general-purpose CAAD software.
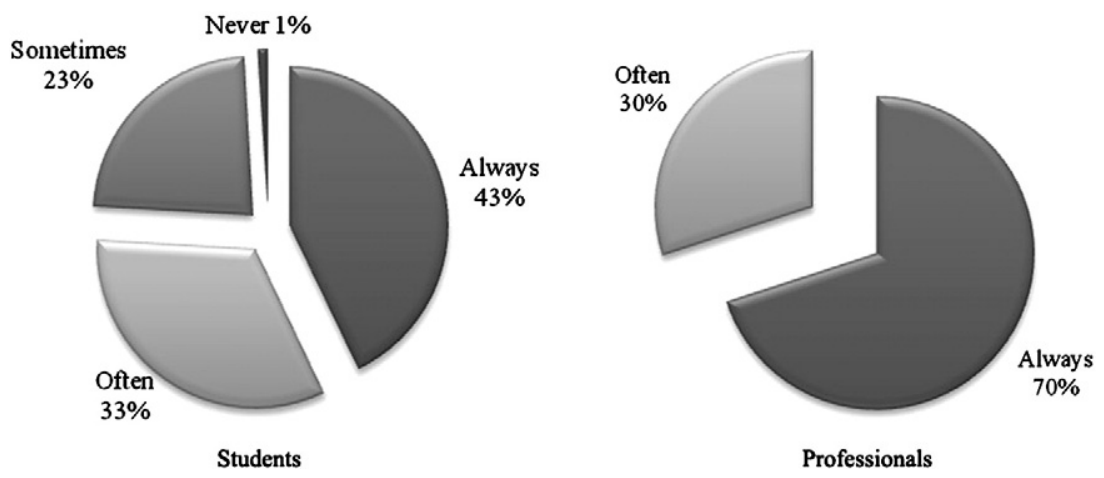

Fig. 8. Percentage distributions of need for domain specific CAD software in interior architectural design. 

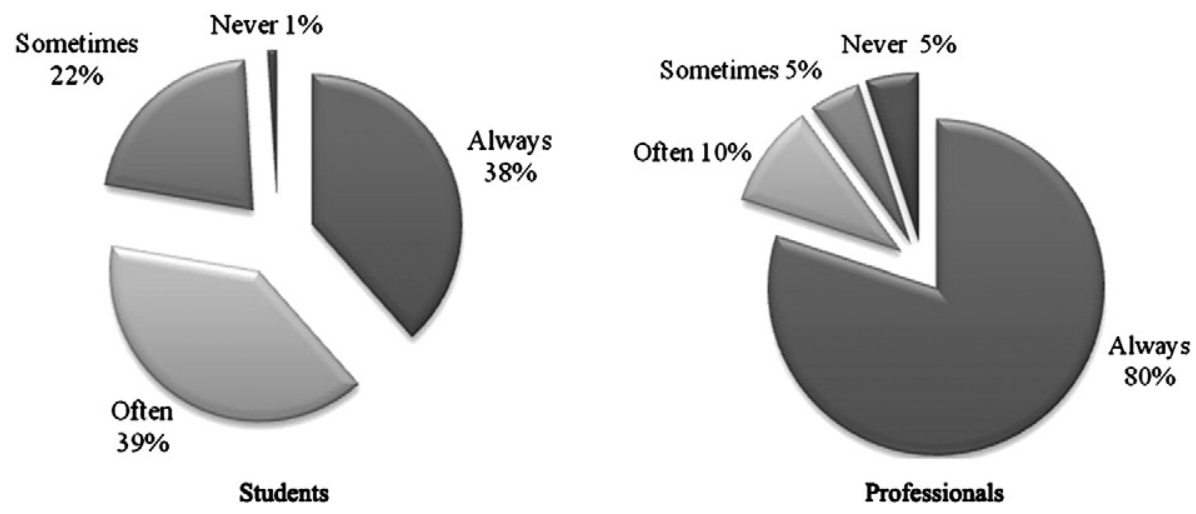

Fig. 9. Percentage distributions of tendency in using domain specific interior architectural software.

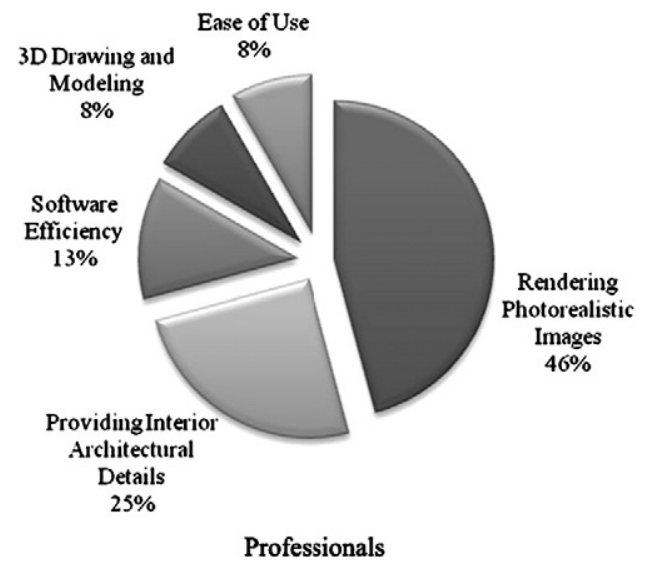

Fig. 10. Percentage distribution of criteria related to the domain specific CAAD software need in interior architectural design.

Based on the findings, the following points may be stated:

- AutoCAD is the most commonly used software in interior architectural education and practice

- Students tend to use different software packages in conceptual, project development and presentation phases. Professionals mostly prefer to use AutoCAD throughout the design process.

- In conceptual phase students prefer Photoshop, due to its 2D graphical representation capabilities and text effects. Professionals prefer to use AutoCAD due to its 'flexibility' and 'sufficiency in 2D drawing' features, and '2D graphical presentation' ability.

- In project development phase, students and professionals utilize AutoCAD because of its 'ease of use', it's potential to provide 'detailed, technical and precise drawings for production'.

- In presentation phase, similarly, AutoCAD is the most preferred software used by users due to its 'general-purpose structure', 'ease of use', 'short processing time' and 'sufficiency in 3D modeling and presentation'

- Users seem to find the general-purpose CAAD software adequate, yet when inquired they state that they need domain specific software package that would provide 'photo-realistic image rendering', 'interior architectural details' and 'easy transition from 2D to 3D'.

- Lastly, when the user needs are classified as 'software features' and 'quality attributes', although the percentage distributions are close, 'ease of use' is the most popular one.

The findings may further be discussed in two parts: First, the performance of the software packages in terms of offering a variety of features; secondly, users' assessments of the software packages.

\subsection{Software packages}

'Drawing' feature analysis between general-purpose and domain specific software shows that neither group meets all the criteria given. General-purpose software packages are not found efficient in drawing interior architectural objects. Similarly, domain specific software

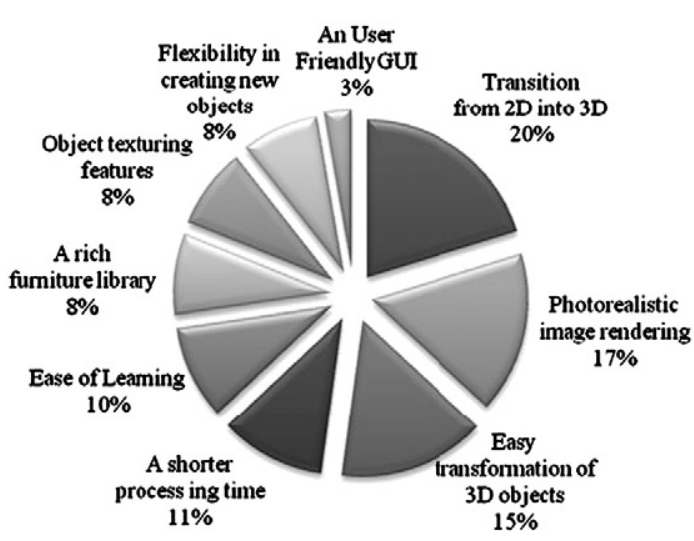

Students

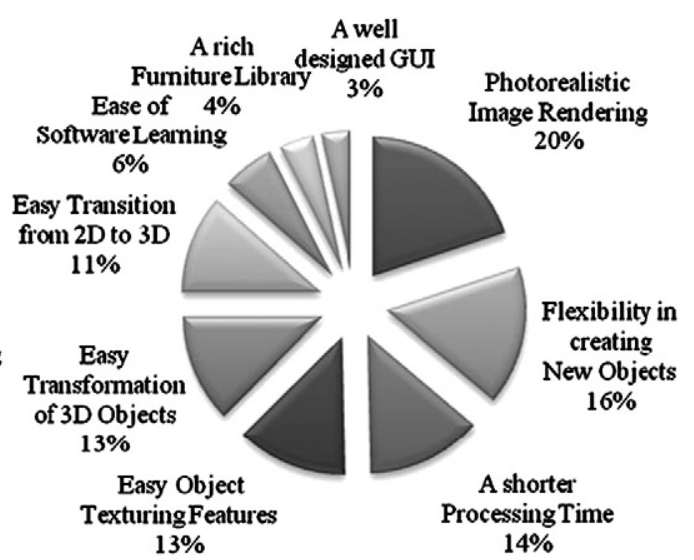

Professionals

Fig. 11. Distributions of preferences for using domain specific CAD software. 
Table 3

Users' needs in terms of software features.

\begin{tabular}{|c|c|c|}
\hline Feature List & User Needs of Students & User Needs of Professionals \\
\hline DRAWING & $\begin{array}{l}\text { Provide an extensive Furniture Library } \\
\text { Provide Architectural Elements (like stairs, lifts ) } \\
\text { Provide Landscape Elements Library } \\
\text { Provide proper 2D Drawing Tools } \\
\text { Provide 3D Modeling Features and Tools }\end{array}$ & $\begin{array}{l}\text { Provide an extensive Furniture Library } \\
\text { Provide 3D Modeling Features and Tools }\end{array}$ \\
\hline TRANSFORMATION & $\begin{array}{l}\text { Provide extensive 3D Geometrical Transformations } \\
\text { Provide efficient Transition between 2D and 3D }\end{array}$ & $\begin{array}{l}\text { Provide extensive 3D Geometrical Transformations } \\
\text { Provide Transition between 2D and 3D }\end{array}$ \\
\hline VIEW & $\begin{array}{l}\text { Provide Photorealistic View } \\
\text { Provide Cameras with Video and Animation Features } \\
\text { Provide 3D Views and Perspectives }\end{array}$ & $\begin{array}{l}\text { Provide Photorealistic View } \\
\text { Provide Cameras with Video and Animation Features } \\
\text { Provide different 3D Views and Perspectives }\end{array}$ \\
\hline RENDERING & $\begin{array}{l}\text { Provide an extensive Material, Texture and Color Library } \\
\text { Provide Photorealistic Materials } \\
\text { Provide Material Editing Features } \\
\text { Provide various Lighting Elements } \\
\text { Provide extensive Lighting Features } \\
\text { Provide Global Rendering (Photorealistic Lighting and Rendering) } \\
\text { Provide extensive Rendering Features }\end{array}$ & $\begin{array}{l}\text { Provide an extensive Material, Texture and Color Library } \\
\text { Provide Photorealistic Materials } \\
\text { Provide Material Editing Features } \\
\text { Provide various Lighting Elements } \\
\text { Provide extensive Lighting Features } \\
\text { Provide Global Rendering (Photorealistic Lighting and Rendering) } \\
\text { Provide extensive Rendering Features }\end{array}$ \\
\hline OTHER FEATURES & $\begin{array}{l}\text { Provide resemblance to AutoCAD in 2D Drawing } \\
\text { Provide resemblance to 3D Studio MAX in 3D Modeling Features } \\
\text { Provide Layering Feature } \\
\text { Provide a Command Line and Shortcuts } \\
\text { Provide User Coordinate Systems (UCS) }\end{array}$ & $\begin{array}{l}\text { Provide Layering Feature } \\
\text { Provide Cost Estimation Features }\end{array}$ \\
\hline
\end{tabular}

packages are not found totally sufficient for interior architectural purposes since they focus on drawing particular objects for particular spaces such as, kitchens and bathrooms.

In 'transformation' features' analysis, domain specific software seem to serve for only the basic operations, lacking maneuvering ability in complex and specific operations. The lacking transformation features should be embedded in a domain specific interior architectural software package. Users would have choice to choose whether they need basic or complex transformation features.

In 'view' features' analysis, software packages offer most of the listed features. Yet, in interior architectural projects, as rendering is important in order to get the right effect of the material and lighting, a domain specific software package should have extensive rendering features as in order to achieve photo-realistic presentation.

'Cost estimation' feature emerges as an important requirement in 'other' feature analysis, displaying the need for calculating the cost of the design in an interior architectural project.

\subsection{User preferences}

User preferences are discussed in terms of:

Software preferences,

Desired software features

Software quality attributes.

Table 4

Users' need in terms of software quality attributes.

\begin{tabular}{|c|c|c|}
\hline Quality Attributes & User Needs of Students & User Needs of Professionals \\
\hline EASE OF USE & $\begin{array}{l}\text { Provide easy 3D Object Modeling } \\
\text { Provide easy Interoperability between 2D and 3D } \\
\text { Provide easy 3D Object Transformation } \\
\text { Provide easy 3D Object View (Perspectives) } \\
\text { Provide easy Material Editing and Attaching } \\
\text { Provide easy Light Editing } \\
\text { Provide easy Object Rendering } \\
\text { Provide easy Software Use (Commands) } \\
\text { Provide easy Interface Use and Perception } \\
\text { Provide easy Software Learning }\end{array}$ & $\begin{array}{l}\text { Provide easy 3D Object Modeling } \\
\text { Provide easy Interoperability between 2D and 3D } \\
\text { Provide easy 3D Object Transformation } \\
\text { Provide easy Material Editing and Attaching } \\
\text { Provide easy Software Use (Commands) } \\
\text { Provide easy Interface Use and Perception } \\
\text { Provide easy Software Learning }\end{array}$ \\
\hline RELIABILITY & $\begin{array}{l}\text { Provide Reliability in 2D Drawing } \\
\text { Provide Reliability in 3D Modeling } \\
\text { Provide Reliability of Software (Recovering Mistakes) }\end{array}$ & \\
\hline EFFICIENCY & $\begin{array}{l}\text { Provide a shorter Processing Time (Quality in Result) } \\
\text { Provide a shorter Rendering Time }\end{array}$ & $\begin{array}{l}\text { Provide a shorter Processing Time (Quality in Result) } \\
\text { Provide a shorter Rendering Time }\end{array}$ \\
\hline FLEXIBILITY & $\begin{array}{l}\text { Provide Flexibility in creating New Objects (instead of object library) } \\
\text { Provide Flexibility in allowing users to Draw Every Shape } \\
\text { Provide Flexibility of Software }\end{array}$ & $\begin{array}{l}\text { Provide Flexibility in creating New Objects (instead of object library) } \\
\text { Provide Flexibility in allowing users to Draw Every Shape (especially } \\
\text { in Furniture Details) } \\
\text { Provide Flexibility of Software }\end{array}$ \\
\hline OTHER ATTRIBUTES & $\begin{array}{l}\text { Provide Interoperability between different Software Packages } \\
\text { Provide Collaboration in a Project } \\
\text { Provide Resemblance to Hand Drawing } \\
\text { Provide an Interesting Software }\end{array}$ & Provide Interoperability between different Software Packages \\
\hline
\end{tabular}



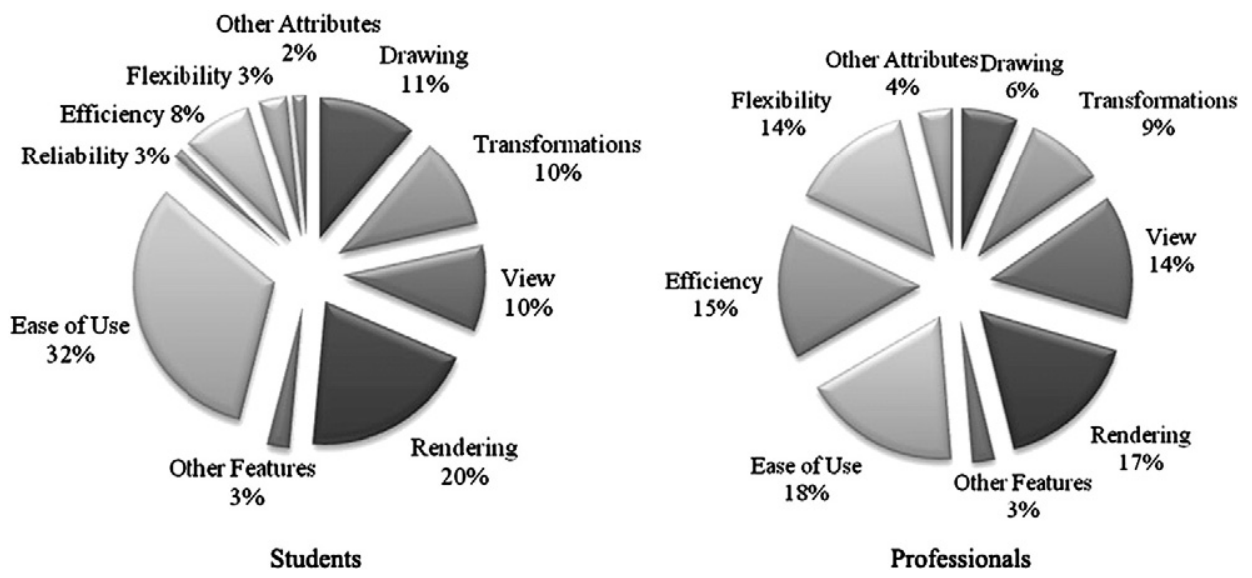

Fig. 12. Preferences in terms of software features and software quality attributes.

\subsubsection{Software preferences}

In this study, it is observed that both in education and in practice computers are utilized extensively and most used software package is AutoCAD, which is a general-purpose 2D drawing and 3D modeling software.

In the conceptual design phase, though Photoshop was not listed in the questionnaire and interviews (since it belongs to a 2D image processing software family), a considerable amount of the students stated that they use Photoshop in their design process. This may largely be due to the students' need of photo-realistic rendering. Overall, $25 \%$ of students stated that they use AutoCAD in this phase, as it is the software being taught in the curriculum.

There is a significant decrease in the number of professionals using a software package during the conceptual design phase. 6 out of 20 professionals do not prefer to use computers in this phase to 'speed up their design process'. They also believe that 'using computers would decrease their creativity'. These results support the view that the existing software packages do not meet some requirements of professionals in conceptual design phase.

In the project development phase, AutoCAD is the most preferred software due to the ability of executing technical details accurately. Also, 3D Studio Max is preferred in this phase, especially when 3D design and rendering are concerned. A domain specific software package for this phase should ideally cover all features required for designing in 2D and 3D.

AutoCAD is again the most commonly used software in the project presentation phase. Although AutoCAD offers several formats for project presentation (such as pdf, dxf), there is still need for other presentation formats in interior architectural practice. It is found out that professionals use different kinds of software packages, such as Microsoft Excel, Word, Powerpoint or Media Player, in this phase for calculating the design cost and preparing project presentation briefs.

\subsubsection{Software features}

Users want to have an extensive 'furniture library'. Such libraries can be found in most of currently used software packages, but a few operate tools to modify properties of furniture's color, texture, size, etc. General-purpose and domain specific software comparisons showed that domain specific software packages have basic object transformation tools. However, these tools do not satisfy the users' needs. The users are in need of varied transformation tools. Users also emphasized the need to have 'photo-realistic view'. They stated that they need extensive 'rendering' and 'lighting' features to achieve more realistic views. Finally, resemblance of commands and utilization to general-purpose software packages is essential in their adaptation to domain specific software.

\subsubsection{Software quality attributes}

Users expect to have more flexible software to create new forms and shapes. Interior architects and students deal with every detail in their projects from lighting to furniture details. They are often having difficulties in drawing furniture details with the possibilities offered by the current CAAD software. The domain specific software package should be designed as a flexible system, to allow users' imagination to develop while presenting new design alternatives. Also, 'reliability' and 'efficiency' related attributes should be comprised to help users generate more sufficient and faster interior architectural projects in a relatively short time.

\section{Propose model}

The analyses and findings of this study enforced the view that there is need for a domain specific software package in interior architecture. Based on the findings, a model for interior domain specific software package may be proposed. The results of the comparison between the general-purpose and domain specific software features form the spine of the model. With these comparisons, overlaps and gaps between these software packages are monitored and integrated into the model. The overlaps determine the shared features of the model, while the gaps determine the domain specific interior architectural requirements. The software features and quality attributes of the proposed model are improved by user

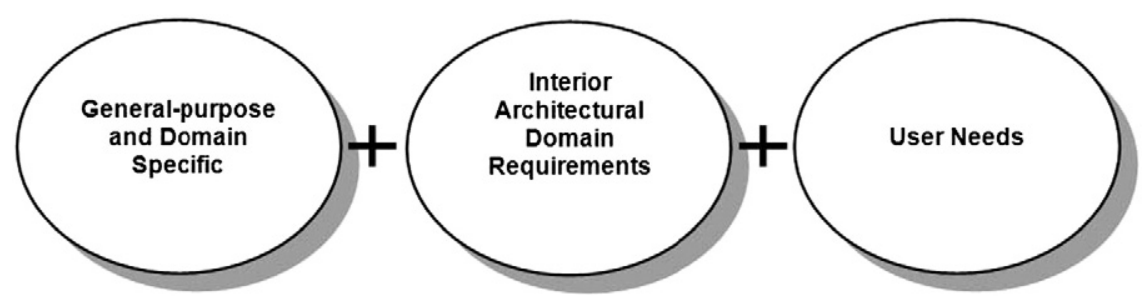

Fig. 13. Proposed model main procedures. 


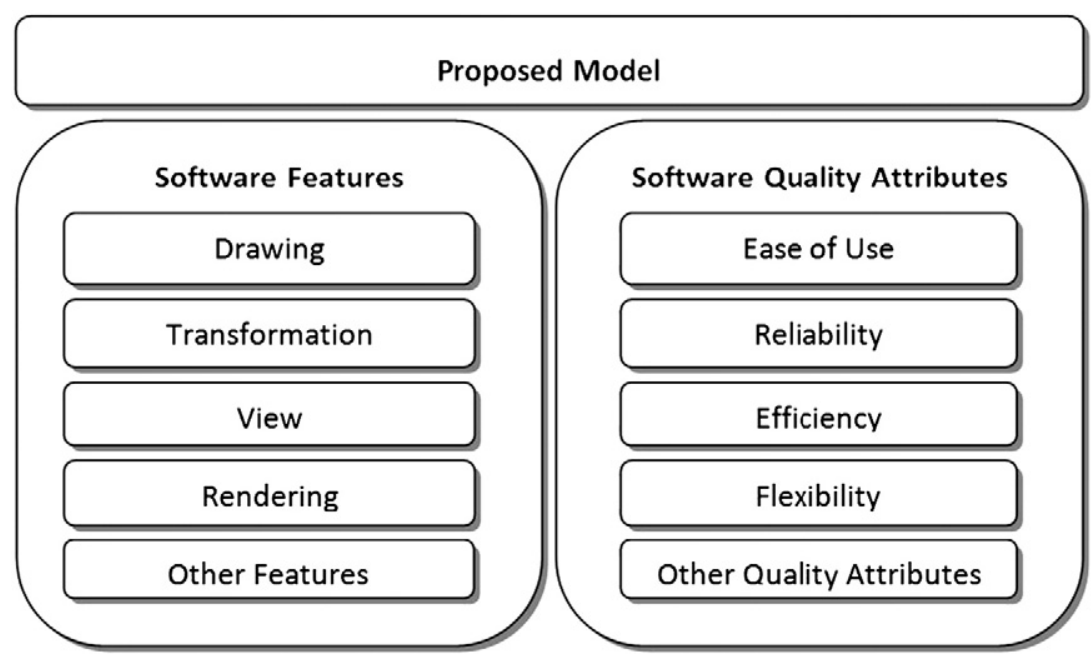

Fig. 14. Proposed model.

questionnaire and interview analyses. The main structure of the proposed model is can be summarized as in Fig. 13.

Fig. 14 represents software features and quality attributes of the model. Software features include detailed information about 'drawing' 'transformation', 'view', 'rendering' and 'other' features. Software quality attributes of the model include 'ease of use', 'reliability', 'effectiveness', 'flexibility' and 'other' attributes.

\subsection{Features of the proposed model}

The proposed model features are grouped under 'drawing', 'transformations', 'view', 'rendering' and 'other' categories. Fig. 15 represents an overall picture of these feature categorizations and their dependency on each other.

A summary of the software features is given in Table 5. The items marked with (o) sign represent the optional items that exist in general-purpose software but do not exist in domain specific ones. The star $\left({ }^{*}\right)$ signs represent the new items added to feature list, as defined by the comparative analysis of this study. These new items in the model are significant in giving clues about interior architectural domain requirements. These items are collected from the question- naires and interviews, and are merged with other features. These items do not exist in general-purpose CAAD software.

Drawing features consist of 2D and 3D objects and symbols (Table 5). The results of CAAD software analysis show that, the main difference between the general-purpose and domain specific software revolves around the capability of drawing 2D and 3D interior architectural elements, like kitchen, bathroom, furniture and accessories. At this point, in order to provide a flexible design environment, the proposed model improves the existing software packages by allowing users to create new objects based on the existing ones. Users may not only import the interior architectural objects from a predefined object library, but also can modify certain properties in the proposed model. Therefore, users are not restricted to use a default set of object libraries.

The 'transformation' analysis revealed that general-purpose software display a comprehensive feature list compared to domain specific ones. This can be interpreted as general-purpose software introducing too many unnecessary transformation features for interior architecture.

In 'view' features, the general outline of the model is again based on general-purpose CAAD software. The results of users needs

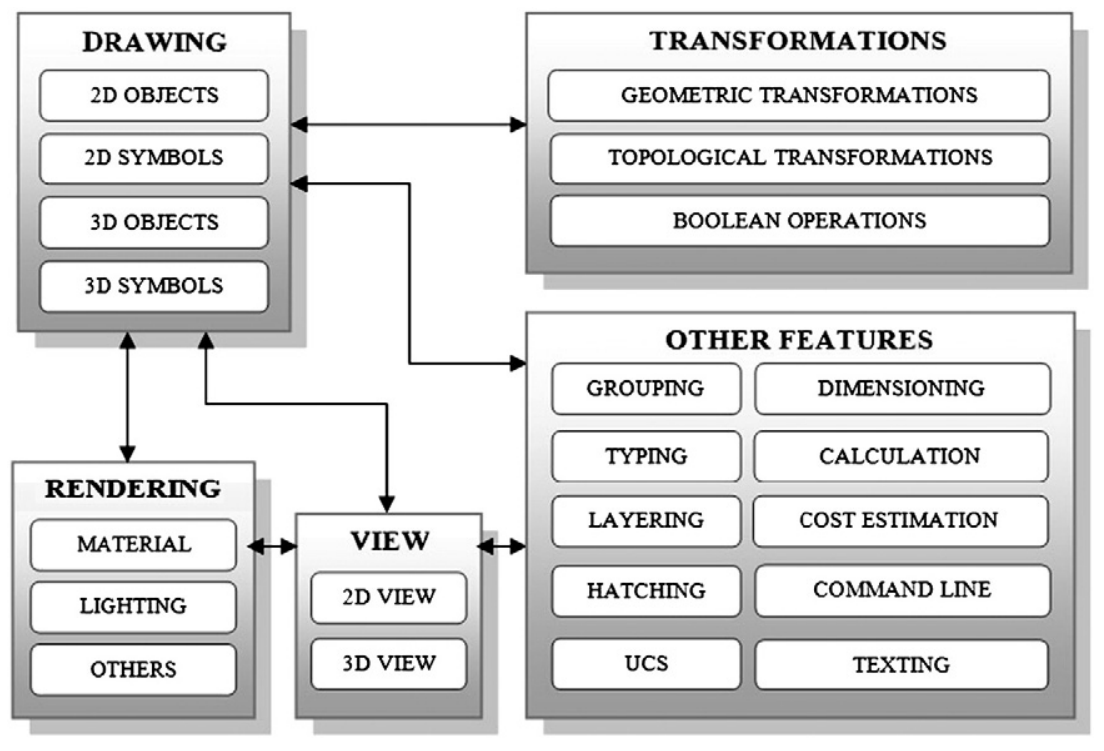

Fig. 15. Software features of the proposed model. 
Table 5

Software features of the proposed model.

\begin{tabular}{|c|c|c|c|}
\hline \multicolumn{4}{|l|}{ PROPOSED MODEL } \\
\hline \multirow{22}{*}{$\begin{array}{l}\text { DRAWING } \\
\text { FEATURES }\end{array}$} & \multirow[t]{4}{*}{ 2D Objects } & \multicolumn{2}{|l|}{ Line Types } \\
\hline & & \multicolumn{2}{|l|}{ Shapes } \\
\hline & & \multicolumn{2}{|l|}{ Grids } \\
\hline & & \multicolumn{2}{|c|}{ Dimensions } \\
\hline & 2D Symbols & \multicolumn{2}{|c|}{ Architectural Symbols } \\
\hline & & \multicolumn{2}{|c|}{ Engineering Symbols } \\
\hline & & Landscape Symbol & \\
\hline & & Kitchen Symbols * & \\
\hline & & Bathroom Symbol & \\
\hline & & Furniture Symbols & \\
\hline & & Accessories * & \\
\hline & 3D Objects & Planes & \\
\hline & & Volumes & \\
\hline & & Quadric Surfaces ( & \\
\hline & & High order Surface & (o) \\
\hline & 3D Symbols & Architectural Sym & \\
\hline & & Landscape Symbol & \\
\hline & & Engineering Symb & \\
\hline & & Kitchen Symbols * & \\
\hline & & Bathroom Symbol & \\
\hline & & Furniture Symbols & \\
\hline & & Accessories * & \\
\hline TRANSFORMATION & Geometric & Copy & Stretch \\
\hline FEATURES & Transformations & Mirror & Extend \\
\hline & & Array & Trim \\
\hline & & Offset & 3D Mirror (o) \\
\hline & & Erase & 3D Array \\
\hline & & Move & 3D Move \\
\hline & & Scale & 3D Rotate \\
\hline & & Rotate & \\
\hline & Geometric & Bend (o) & \\
\hline & Deformations & Taper (o) & \\
\hline & & Twist (0) & \\
\hline & Topological & Extrude (o) & \\
\hline & Transformations & Sweep (o) & \\
\hline & & Loft $(0)$ & \\
\hline & & Wave (o) & \\
\hline & & Noise (0) & \\
\hline & Boolean & Union & \\
\hline & Operations & Subtract & \\
\hline & & Intersect & \\
\hline VIEW FEATURES & 2D View & Zoom & \\
\hline & & Pan & \\
\hline & & 2D Wireframe & \\
\hline & & 2D Hidden (o) & \\
\hline & & Viewports & \\
\hline & & Section View & \\
\hline & 3D View & 3D Wireframe & Section View \\
\hline & & 3D Hidden & 3D Orbit \\
\hline & & Shaded & Camera \\
\hline & & $\begin{array}{l}\text { Perspective View } \\
\text { Axonometric (o) }\end{array}$ & Animation \\
\hline RENDERING & Material Library & $\begin{array}{l}\text { Axonometric }(0) \\
\text { Photo realistic tex }\end{array}$ & \\
\hline FEATURES & & library * & \\
\hline & & Photo realistic col & \\
\hline & & library * & \\
\hline & & Extensive library & alog * \\
\hline & Material Operations & Material Creation & \\
\hline & & Material Editing & \\
\hline & & Material Import & \\
\hline & & Mapping Direction & \\
\hline & & Mapping Frequen & \\
\hline & & Texture Mapping & \\
\hline & Lighting Elements & Spotlight (o) & \\
\hline & & Direct Light (o) & \\
\hline & & Sunlight & \\
\hline & & Omni & \\
\hline & Light Editing & Radiosity & \\
\hline & & Intensity & \\
\hline & & Brightness & \\
\hline & & Shading & \\
\hline & & Reflection & \\
\hline & & Refraction & \\
\hline & & Resolution * & \\
\hline & Rendering Method & Local Rendering & \\
\hline & & Global Rendering & \\
\hline
\end{tabular}

Table 5 (continued)

\begin{tabular}{ll}
\hline OTHER FEATURES & Grouping \\
& Typing \\
& Layering \\
& Hatching \\
& Dimensioning \\
& Calculation (area etc.) \\
& Cost Estimation * \\
& Command Line * \\
& User Coordinate System (o) \\
\hline
\end{tabular}

* New features added.

(o) Optional features.

presented in the previous analyses revealed that 'view' operations gain importance during presentation phase of design process and the important features for users are 'photo-realistic view', 'camera', 'animation' and 'perspectives'. The proposed model improves 'rendering' features of general-purpose software by adding 'photo realism' to 'material library' and 'light editing' features. The 'photo realism' issue has an important role in the formation of the proposed model. The students and the professionals want to visualize their projects as real-looking as possible, not in sketch view. Therefore, this model provides and emphasizes the need for 'photo-realistic' interior views, which would improve their visual communication between their instructors, their colleagues and their clients.

The 'other' features of the proposed model introduce a new feature: 'cost estimation', which is lacking in the analyzed generalpurpose CAAD software. This feature is an indispensable one in domain specific software used in practice. Professionals have to calculate the approximate or exact cost of the project with all expenses included. It may be asserted that this feature will be useful for the students and will make their adaptation to the professional practice much easier.

\subsection{Quality attributes of the proposed model}

Quality attributes of the model cover the issues related to 'ease of use', 'efficiency', 'reliability', 'flexibility' and 'other' attributes (Fig. 16), which are gathered through the questionnaire and the interview analyses. Fig. 16 also shows their relationships to each other.

The initial issue in quality attributes is the 'ease of use'. It is observed that among the findings of the questionnaire and the interviews 'ease of use' is the most significant attribute among others. Students and professionals mostly stated that a software package should provide 'ease of use' in terms of 'handling the software and its commands', 'easy interoperability between 2D and 3D', and 'ease of learning'. The attributes related to 'ease of use' would differentiate the proposed model from other software existing in education and practice.

The second quality attribute 'reliability' can be defined as the working of the system without errors and failures, while correctly delivering services as expected by the user [24]. In the proposed model, software 'reliability' is interpreted as the systems' being 'reliable during 2D and 3D drawing' and being 'reliable in recovering failures' (Table 6). This interpretation is based on the findings of the student's questionnaires.

Another quality attribute is software 'efficiency', which comprises the issues concerning the functioning of the system in a comparatively shorter processing time. Software 'efficiency' together with the user performance and knowledge is a significant factor in shortening the design and presentation time of the project. The proposed model offers 'shorter rendering and processing time' and 'high quality of the result' attributes to improve the software quality (Table 6 ).

'Flexibility' is another attribute affecting the software quality. Within the context of this study, 'flexibility' of the proposed model 


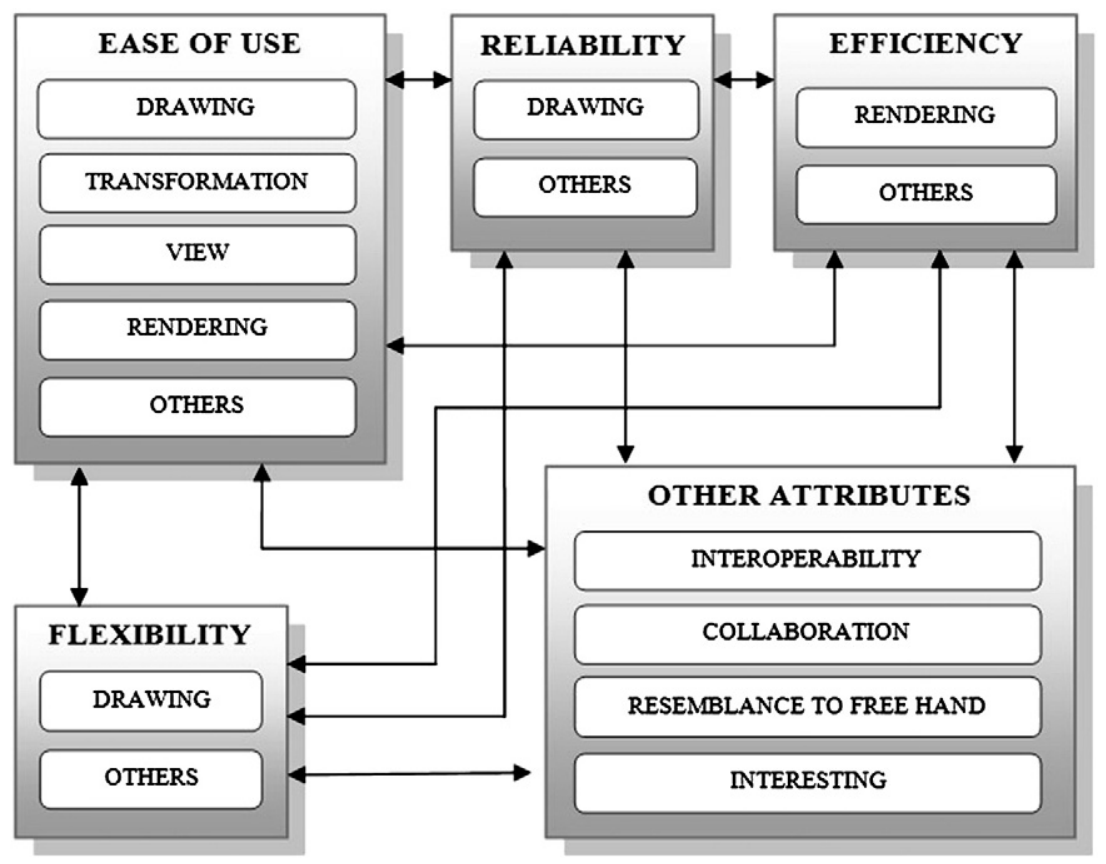

Fig. 16. Software quality attributes of the proposed model.

depends on how much freedom the system provides for its users to design the intended shape, geometry or project. The related issues are the flexibility in 'creating new objects' and in 'creating new forms and shapes', instead of using them from an object library (Table 6). Hence, this model would provide users to design any object in any level of detail.

'Other' quality attributes are seldom considered to be important ones. However, these are vital items for the future versions of a software package and actually a software model can be developed

Table 6

Software features of the proposed model.

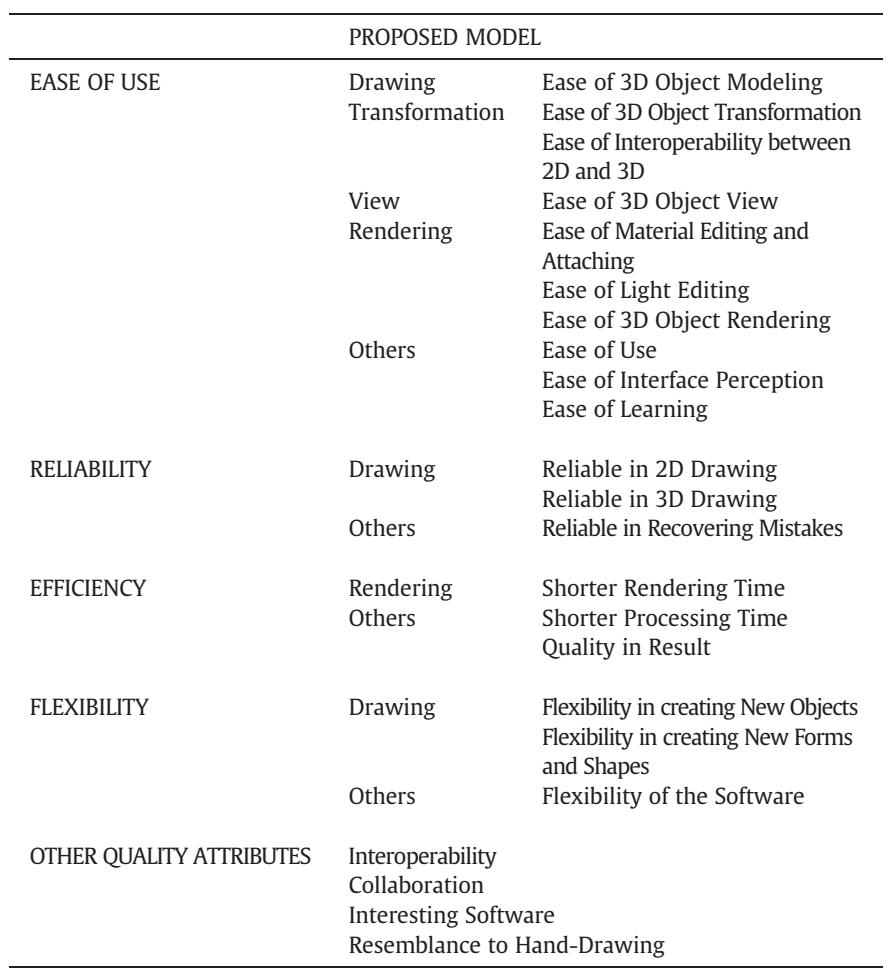

considering only one of these items. For instance, 'collaboration', which is categorized under 'other' quality attributes, allow students to share and develop richer ideas during design process and to improve their team-work skills [25].

\section{Conclusion}

In this study, the discussion is shaped around the two-fold question of whether there is a need for a fully dedicated software package for interior architecture and what features it should hold. Although interior architecture is a different discipline from architecture, there is no specific software for interior architecture that is commonly used. Instead, architectural software packages are used for interior architectural purposes. The inefficiencies may be monitored both in professional life and in education. In the market, the specific needs of interior architecture are met by individually developed software by individual firms. In education, architectural software packages are customized by the students themselves for interior architectural design process. As such, interior architecture misses the opportunity to manifest itself once more as a separate discipline and becomes engulfed by architecture.

The results of this study showed that interior architecture has different requirements than architecture and it would benefit from a domain specific software package. In this study, general-purpose and domain specific CAAD software packages and their features are analyzed. Then, user needs in interior architecture are determined from questionnaires and interviews. Finally, a software model is proposed by combining the features and user needs.

It may be asserted that if a specific software package for interior architecture would be developed based on the proposed model, it will constitute a medium for the profession to put forth its potentials. Presentation has always been a crucial part of the discipline, perhaps more than it is for architecture, since the presumed interior atmosphere is more convenient for everyone to comprehend, compared to the urban impact of a building mass. The findings of our study once more justified that students and professionals tend to use the maximum number of software packages in the presentation stage of design. With the emergence of computer assisted drawings, the importance of presentation grew in interior architectural education and market. Having a 
realistic and impressive presentation makes instructors, students and customers more satisfied [26]. Instead of presenting still images, it is more important to generate simulations, animating how people will use or how the interior will behave when the project is realized [27]. Software packages, embellished with simulation possibilities such as representing the behavior of water in the inside or the outside conditions (sun, wind, rain, etc.), or assessing the acoustics behavior of an interior, or showing the lighting quality of an interior environment, independent of the architectural shell -i.e. experienced in default interiors- could be beneficial for indicating the kind of atmosphere that is desired. As such, interior architectural decisions could influence the architectural ones, rather than being dictated by them.

For interior architects it may be beneficial to model objects using realistic and complex geometries rather than quadric surfaces. These are high-order surfaces, including spline fits, curved surfaces, patches and grid representations. It may be assumed that the advanced requirements about simulations and high-order surfaces will become common place soon in interior architectural education and practice. These requirements would be unnecessary to be integrated into a general purpose software, while simultaneously increasing the price of the software, but a domain specific software is an excellent opportunity to make these available to interior architects.

Finally, it needs to be noted that the proposed model constitutes a framework intended for software developers to utilize in order to develop an interior architectural domain software package. The model should be implemented by future studies and the resulting software should be assessed by interior architectural students and professionals. Changes may be expected after user assessments. The interface design and issues pertaining to the menus are not mentioned within the context of this study and are still open to improvement. Although observations are made with participating professionals, the assumptions of this study still remain limited due to the absence of a structured monitoring of interior architectural students while they are using the specified software packages. The proposed model is prone to further development through such observations.

\section{Acknowledgments}

This article is based on the second author's M.F.A thesis in interior architecture, supervised by the first author. The authors would like to thank all the participating students and professionals for their input to this study.

\section{References}

[1] P. Szalapaj, CAD Principles for Architectural Design: Analytical Approaches to Computational Representation, Architectural Press, Oxford, 2001

[2] D. Kurman, How to Design Space? in: T. Sasada, S. Yamaguchi, M. Morozumi, A. Kaga, R. Homma (Eds.), CAADRIA '98: Proceedings of The Third Conference on Computer Aided Architectural Design Research in Asia, Birkhäuser, Basel, 1998, pp. 317-325.
[3] J.S. Gero, A locus for knowledge-based systems in CAAD education, in: $M$. McCullough, W. Mitchell, P. Purcell (Eds.), The Electronic Design Studio: Architectural Knowledge and Media in the Computer Era, MIT Press, Cambridge, 1990, pp. 49-60.

[4] C.M. Eastman, Building Product Models: Computer Environments Supporting Design and Construction, CRC Press, Boca Raton, 1990.

[5] L. T. T. Lok, A Critical Survey of Software Packages for Use by Interior Designers, unpublished PhD Thesis, University of Wales, Aberystwyth, 2004.

[6] J. Kurtich, G. Eakin, Interior Architecture, John Wiley \& Sons, Inc., New York, 1993.

[7] J. Coles, N. House, The Fundamentals of Interior Architecture, Ava Publishing House, West Sussex, 2007.

[8] L.K. Havenhand, A View from the Margin: Interior Design, Design Issues 20 (4) (2004) 32-42.

[9] C. Chu, Interior design in Hong Kong: A practice in transition, Design Issues 19 (3) (2003) 37-47.

[10] M.D. Gross, Roles for Computing in Schools of Architecture and Planning, Journal of Architectural Education 48 (1) (1994) 56-64.

[11] M.J. Clayton, R.B. Warden, T.W. Parker, Virtual construction of architecture using 3D CAD and simulation, Autom. Constr. 11 (2) (2002) 227-235.

[12] S. Clemons, J. McCullough, Attitudes of interior designers toward CADD and CADD education, Journal of Interior Education and Research 15 (2) (1989) 29-34.

[13] M. McConnell, L. Waxman, Three-dimensional CAD use in interior design education and practice, Journal of Interior Design 25 (1) (1999) 16-25.

[14] J.-H. Lee, W. Qian, Color your feeling - Design support system for color coordination, in: J.P. Van Leewen, H.J.P. Timmermans (Eds.), Recent Advances in Design and Decision Support Systems in Architecture and Urban Planning, Kluwer Academic Publishers, Dordrecht, 2004, pp. 113-125.

[15] T. Brito, M.J. Fonseca, J.A. Jorge, DekoSketch-Towards calligraphic approaches to interior design, 23 rd eCAAde Proceedings, Portugal, 2005, pp. 665-670.

[16] T. Dorta, Virtuality and creation? The emptiness of computers in conceptual design. Elisava Temes de Disseny Journal, 23 (2006) 160-170.

[17] S.Y. Choo, K.S. Heo, J.H. Seo, M.S. Kang, Augmented reality - Effective assistance for interior design, 27th eCAADe Proceedings, İstanbul, 2009, pp. 649-656.

[18] H. Rashed-Ali, I. Solovyova, D. Ohlenbusch, M. Rees, Integration and interdisciplinarity in the design studio, an experimental approach, SOLAR 2010 Conference Proceedings, Phoenix, 2010.

[19] B. Succar, Building information modeling framework: A research and delivery foundation for industry stakeholders, Autom. Constr. 18 (2009) 357-375.

[20] B. Dalziel, N. Ostime, Architect's Job Book, RIBA, London, 2008.

[21] B. Lawson, How designers think: the design process demystified, Architectural Press, Oxford, 2006.

[22] Y.S. Kim, Knowledge Aided-Design System for Intelligent Building Design, in: G. Jingwen, W. Zhaoji (Eds.), CAADRIA' 99: Proceedings of the Fourth Conference on Computer Aided Architectural Design Research in Asia, Shanghai Scientific and Technological Literature Publishing House, Shangai, 1999, pp. 305-312.

[23] B. Senyapılı, İ. Basa, The Shifting Tides of Academe: Oscillation between Hand and Computer in Architectural Education, International Journal of Technology and Design Education 16 (2006) 273-283.

[24] I. Somervile, Software Engineering, Pearson Education Limited, Edinburgh, , 2004.

[25] A.F. Karakaya, B. Senyapili, Rehearsal of professional practice: Impacts of webbased collaborative learning on the future encounter of different disciplines, International Journal of Technology and Design Education 18 (2007) 101-117.

[26] I.-C. Huang, T.W. Chang, A study of oversized display in supporting design communication: Focus on interior design problems, in: J.P. Van Leeuwen, H.J.P. Timmermans (Eds.), Porgress in Design and Decision Support Systems in Architecture and Urban Planning, Eindhoven University of Technology, Eindhoven, 2006, pp. 289-301.

[27] B. Westerdahl, K. Suneson, C. Wernemyr, M. Roupe, M. Johansson, C.M. Allwood, Users' evaluation of a virtual reality architectural model compared with the experience of the completed building, Autom. Constr. 15 (2) (2006) 150-165. 